\title{
EMERGING MARKET BONDS: HIGH YIELDS AND DIVERSIFICATION?
}

Mitchell Ratner, Rider University, Lawrenceville, New Jersey, U.S.A. Chih-Chieh (Jason) Chiu, Rider University, Lawrenceville, New Jersey, U.S.A.

dx.doi.org/10.18374/JIFS-20-1.2

\begin{abstract}
This study examines the potential diversification benefits of adding emerging market bonds to portfolio of US stocks from July 2004 through July 2019 . The results indicate that relatively higher returns can be earned by investing in local currency emerging market bonds during the full sample period. While emerging market bonds offer diversification benefits, they do not provide a hedge to portfolio risk. In times of economic/political turmoil, emerging market bonds do not afford a safe haven. The greatest hedging benefits (among bonds) are provided by investing in diversified portfolio of US bonds. To a lessor degree, hedging benefits are also achieved through investment in a diversified portfolio of international bonds from developed countries.
\end{abstract}

Keywords: bonds, emerging markets, diversification, hedge 